\title{
PENGARUH PENGAMBILAN RESIKO, INOVASI, PROAKTIF, COMPETITIVE AGGESSIVENESS DAN OTONOMI TERHADAP KINERJA USAHA KONVEKSI
}

\author{
Dita dan Lydiawati Soelaiman \\ Program Studi Manajemen Fakultas Ekonomi \\ Universitas Tarumanagara, Jakarta \\ Email: dita.gani97@gmail.com
}

\begin{abstract}
The purpose of this research is to increase the competitiveness of convection business in facing challenges from competitors by testing whether: 1) risk taking can influence convection business performance 2) innovativeness can influence convection business performance 3) proactiveness can influence convection business performance 4) Competitive aggressiveness can influence convection business performance and 5) autonomy can influence convection business performance. The sample used amounted to 60 respondents having convection in west Jakarta and using non-probability sampling as a sample selection technique . The result prove that the significant impact between risk taking, innovativeness and autonomy to business performance and has no significant impact to proactiveness and competitive aggressiveness to business performance.
\end{abstract}

Kata kunci: risk taking, innovativeness, proactiveness, competitive aggressiveness, autonomy, business performance

Abstrak: Tujuan dari penelitian ini adalah untuk meningkatkan daya saing usaha konveksi dalam menghadapi tantangan dari para pesaing dengan menguji apakah : 1) Pengambilan resiko dapat mempengaruhi kinerja usaha konveksi 2) Inovasi dapat mempengaruhi kinerja usaha konveksi 3) Proaktif dapat mempengaruhi kinerja usaha konveksi 4) Competitive aggressiveness dapat mempengaruhi kinerja usaha konveksi dan 5) Otonomi dapat mempengaruhi kinerja usaha konveksi. Sampel yang digunakan dalam penelitian ini berjumlah 60 orang responden yang memiliki konveksi di Jakarta Barat dan menggunakan metode nonprobability sampling sebagai teknik pemilihan sampel. Hasil menunjukkan terdapat pengaruh signifikan antara pengambilan resiko, inovasi dan otonomi terhadap kinerja usaha dan tidak terdapat pengaruh yang signifikan antara proaktif dan competitive aggressiveness terhadap kinerja usaha.

Kata kunci: Pengambilan resiko, inovasi, proaktif, competitive aggressiveness, otonomi

\section{LATAR BELAKANG}

Setiap perusahaan yang didirikan pasti memiliki tujuan yang baik atas perusahaannya. Dalam upaya mencapai tujuan tersebut diperlukan pula kinerja yang baik. Menurut Wibowo (2010) kinerja merupakan salah satu tingkat pencapaian dalam melaksanakan suatu kegiatan kebijakan untuk dapat mewujudkan tujuan, misi dan visi perusahaan.

Knight (2000) menyatakan di dalam era globalisasi, UKM yang menerapkan entrepreneurial orientation (EO) akan memiliki kinerja yang lebih baik dibandingkan dengan usaha yang tidak menerapkan orientasi kewirausahaan. Menurut Knigh (2000) UKM harus memiliki EO agar dapat bertahan dan dapat mengalahkan para pesaingnya. Agar perusahaan 
memiliki kinerja yang lebih baik diharapkan perusahaan dapat menerapkan dimensi dari EO juga.

Ketika seorang memutuskan untuk memulai berwirausaha maka ini adalah awal seorang wirausaha telah mengambil resiko. Menurut Lumpkin dan Dess (2001) pengambilan resiko adalah tindakan seorang pengusaha yang berani dalam memanfaatkan sumber daya yang ia miliki untuk dapat menjalankan usahanya meskipun tidak ada kepastian keberhasilan yang akan diperoleh. Perusahaan diharapkan dapat menunjukan keberanian dalam mengambil resiko yang ada untuk dapat meningkatkan kinerja usaha.

Selain pengambilan resiko, untuk dapat meningkatkan kinerja diperlukan juga inovasi secara terus-menerus. Menurut Nanda (2015) inovasi merupakan keinginan seorang wirausaha untuk dapat menciptakan dan menghasilkan sebuah ide baru, dan mencoba sesuatu hal baru yang berbeda dari yang sudah pernah ada, serta berani mengadopsi ide baru atau metode baru untuk diterapkan di bisnis, lalu menerapkan inovasi dalam bisnis. Calantone, Cavusgil dan Zhao (2002) menyatakan bahwa inovasi memiliki dampak positif terhadap kinerja usaha dan juga berkontribusi terhadap daya saing, dengan memfasilitasi pemikiran kreatif dalam pembelajaran kegiatan perusahaan.

Selain itu untuk dapat meningkatkan kinerja diperlukan juga sifat proaktif. Menurut Lumpkin dan Dess (2001) sikap proaktif adalah seorang pengusaha yang mencerminkan proses dalam mencari peluang baru dengan mengembangkan produk atau jasa yang akan dipasarkan. Menurut Hughes dan Morgan (2007) proaktif cenderung berkaitan dengan kinerja usaha yang unggul karena mengimplementasikan pelanggan, memahami kebutuhan pelanggan, memastikan, mencari tahu kebutuhan pelanggan dan mencari tahu nilai dari pesaing sebelum memberi penawaran kepada pelanggan.

Competitive aggressiveness juga merupakan salah satu yang diperlukan untuk meningkatkan kinerja. Menurut Lumpkin dan Dess (1996) competitive aggressiveness merupakan respon dari pengusaha kepada pesaing untuk dapat mengungguli pesaingnya. Menurut Ernawati (2016) Competitive aggressiveness dapat diperoleh perusahaan dengan memiliki cara budaya organisasi yang baik, konten strategi dan juga kinerja usaha yang baik. Competitive aggressiveness sangat diperlukan dalam perusahaan untuk meningkatkan kinerja usaha sehingga dapat bersaing di setiap sektor industri yang terus semakin kuat.

Hal terakhir dari orientasi kewirausahaan yang diperlukan dalam meningkatkan kinerja ialah otonomi. Menurut Lumpkin dan Dess (1996) otonomi adalah kemandirian dalam kerja berkelompok yang memiliki pengetahuan yang luas serta memiliki tindakan independen dari pemegang peran dalam perusahaan. Menurut Hughes dan Morgan (2007) kehadiran Otonomi seharusnya mendorong fleksibilitas yang lebih besar dalam memfasilitasi respons yang aktif dan reaktif terhadap suatu perubahan sehingga berpengaruh terhadap perbaikan performa bisnis.

\section{KAJIAN TEORI}

\section{Pengambilan Resiko}

Menurut Basrowi (2011 :119) pengambilan resiko adalah sesuatu hal yang selalu dikaitkan dengan kemungkinan terjadinya sesuatu hal yang akan merugikan usaha secara tidak terduga dan tidak diharapkan

Menurut Keh, Foo, dan Lim (2002 :126) "risk taking is the probability that an entrepreneur is able to successfully turn an idea into an opportunity" Pengambilan resiko berdasarkan definisi diatas merupakan sebuah peluang dimana seorang wiraswasta berhasil untuk mengubah suatu ide menjadi sebuah kesempatan 


\section{Inovasi}

Menurut Ramadani dan Gerguri (2011 :269) "Innovation is a process of transforming the new ideas, new knowledge into new products and services" inovasi berdasarkan definisi diatas adalah proses perubahan ide-ide dan pengetahuan baru untuk menciptakan produk atau jasa yang baru.

Menurut Kristiawan et al (2018:3) inovasi merupakan suatu ide, barang atau metode yang dirasakan atau diamati sebagai suatu hal yang baru bagi seseorang atau sekelompok orang, baik itu berupa hasil diskoveri maupun invensi

\section{Proaktif}

Menurut Hughes dan Morgan (2007: 653-654) "Proactiveness is likely to be valuable in securing superior performance returns because it implies customer-centrality given the need to understand customers, ascertain and exploit their needs, and actively deconstruct the value package of competitors to generate superior offerings" Berdasarkan definisi diatas sifat proaktif memiliki nilai yang berarti terhadap keamanan performa dalam timbal balik karena itu terpusatkan kepada suatu hal yang perlu dipahami oleh konsumen, memastikan dan mengeksploitasi kebutuhan mereka dan secara aktif menganalisa nilai dari sesuatu hal yang unggul yang ditawarkan oleh pesaing.

Johannessen, J.A., Olaisen, J. \& Olsen, B. (1999:4) mendefinisikan proaktif sebagai "Proactiveness is the ability to create opportunities or the ability to recognize or anticipate and act on opportunities (or dangers) when they preset themselves" Proaktif berdasarkan definisi diatas merupakan kemampuan untuk menciptakan kesempatan atau keahlian untuk mengenali ataupun mengantisipasi dan bertindak atas peluang (bahaya) ketika mereka memprioritaskan dirinya sendiri

\section{Competitive Aggressiveness}

Menurut Rauch et al (2009 :7) "Competitive aggressiveness is "The intensity of a firm's effort to outperform rivals and is characterized by a strong offensive posture or aggressive responses to competitive threats" competitive aggressiveness berdasarkan definisi diatas adalah intensitas sebuah perusahaan yang berupaya untuk mengungguli pesaing dan dicirikan dengan struktur yang kuat ataupun respon agresif terhadap rintangan

Lumpkin et al (dalam Jahangir, Arash,Amer 2013:27) "competitive aggressiveness is "The intensity of firm's, characterized by a strong offensive posture or aggressive responses to the actions of competitors" competitive aggressiveness berdasarkan definisi diatas adalah intensitas sebuah perusahaan, ditandai dengan sebuah struktur yang kuat atau respon yang agresif terhadap pesaingnya.

\section{Otonomi}

Menurut Lumpkin dan Dess (1996:141) "autonomy is implied by the rights of owner" otonomi berdasarkan definisi diatas adalah otonomi yang dinyatakan oleh hak-hak pemilik.

Lumpkin and Dess (1996:141) "Autonomy is the ability to make decisions and then take action on those decisions independently, without the limitations of the organization" Otonomi berdasarkan definisi diatas adalah kemampuan untuk dapat mengambil keputusan dan dapat melakukan tindakan atas keputusan secara independen, tanpa ada batasan dari organisasi

\section{Kinerja Usaha}

Menurut Suci (2009:48), kinerja merupakan tingkatan pencapaian atau prestasi dari perusahaan dalam periode waktu tertentu. Kinerja Perusahaan adalah hal yang sangat menentykan dalam perkembangan perusahaan. 
Purnomo dan Lestari (2010:146) menyatakan bahwa kinerja usaha merupakan ukuran keberhasilan sebuah perusahaan dalam mencapai tujuannya

\section{Kaitan antara pengambilan resiko dan kinerja perusahaan}

Terdapat banyak studi penelitian yang mendukung pengaruh positif antara pengambilan resiko dan kinerja usaha. Contohnya penelitian Menurut Rauch et al (2009) menyatakan bahwa terdapat hubungan positif antara pengambilan risiko dan kinerja usaha yang dianggap sebagai pandangan yang dominan

Menurut Hughes dan Morgan (2007) pengambilan resiko mempunyai hubungan positif terhadap kinerja usaha. Penelitian ini menunjukan bahwa perusahaan perlu menunjukkan keberanian untuk mengambil resiko dan menantang bisnis yang ada untuk meningkatkan kinerja .

$H_{1}$ : : Terdapat pengaruh yang signifikan antara pengambilan resiko dengan kinerja usaha konveksi di Jakarta Barat

\section{Kaitan antara inovasi dan kinerja usaha}

Pada penelitian Hughes dan Morgan (2007) inovasi dalam menjalankan suatu kegiatan yang besar akan memerlukan biaya yg besar. Walaupun keberhasilan sering kali bergantung pada komersialisasi, namun dengan menerapkan inovasi pada perusahaan akan dapat merubah mekanisme pembelajaran dan pasar dengan pandangan dan persepsi organisasi yang baru sehingga akan dapat berkontribusi terhadap kinerja usaha

Hasil serupa juga dikemukakan oleh Calantone, Cavusgil dan Zhao (2002) menyatakan bahwa inovasi memiliki dampak positif terhadap kinerja usaha dan juga berkontribusi terhadap daya saing, dengan memfasilitasi pemikiran kreatif dalam pembelajaran kegiatan perusahaan

$\mathrm{H}_{2}$ : Terdapat pengaruh yang signifikan antara inovasi dengan kinerja usaha konveksi di Jakarta Barat

\section{Kaitan antara proaktif dan kinerja usaha}

Beberapa studi telah mempelajari hubungan antara proaktif dengan kinerja usaha seperti penelitian yang diteliti oleh Hughes dan Morgan (2007) proaktif cenderung berkaitan dengan kinerja usaha yang unggul karena mengimplementasikan pelanggan, memahami kebutuhan pelanggan, memastikan, mencari tahu kebutuhan pelanggan dan mencari tahu nilai dari pesaing sebelum memberi penawaran kepada pelanggan.

Dan juga sesuai dengan penelitian yang dikemukakan oleh Wright et al (1995) keunggulan dalam proaktif yaitu peningkatan daya perusahaan terhadap sinyal pasar dan kesadaran kebutuhan pelanggan sehingga proaktif berkaitan dengan kinerja karena mereka dapat merespon sinyal pasar.

\section{H3: Tidak terdapat pengaruh yang signifikan antara proaktif dengan kinerja usaha konveksi di Jakarta Barat}

\section{Kaitan antara competitive aggressiveness dan kinerja usaha}

Terdapat banyak studi penelitian yang mendukung pengaruh positif antara competitive aggressiveness terhadap kinerja usaha salah satunya menurut Setiawan, Erdogan dan Ogunlana (2015) menyatakan bahwa competitive aggressiveness telah dianggap sebagai upaya perusahaan untuk mengalahkan pesaingnya secara langsung dan dengan penuh semangat

Hasil serupa juga sesuai dengan penelitian menurut Lumpkin dan Dess (1996) competitive aggressiveness dapat meningkatkan kinerja karena penekanan pada out-doing dan out-manuver pesaing dan dapat memperkuat daya saing bagi perusahaan dengan mengorbankan saingan. $\mathbf{H}_{4}$ : 
Terdapat pengaruh yang signifikan antara competitive aggressiveness dengan kinerja usaha konveksi di Jakarta Barat

\section{Kaitan antara otonomi dan kinerja usaha}

Menurut Hughes dan Morgan (2007) kehadiran Otonomi seharusnya mendorong fleksibilias yang lebih besar dalam memfasilitasi respons yang aktif dan reaktif terhadap suatu perubahan. Meskipun beberapa kerangka koordinasi masih diperlukan, sehingga otonomi berpengaruh terhadap perbaikan performa bisnis

Menurut Bandura (1997) bahwa Otonomi memiliki hubungan positif terhadap kinerja usaha karena diyakini otonomi membuat kepuasan dalam kerja karena karyawan memiliki lebih banyak kebebasan untuk menentukan usahanya.

H2: $_{2}$ Terdapat pengaruh yang signifikan antara otonomi dengan kinerja usaha konveksi di Jakarta Barat

Berdasarkan uraian kaitan antar variabel di atas, maka model penelitian yang digunakan dalam penelitian ini adalah sebagai berikut.

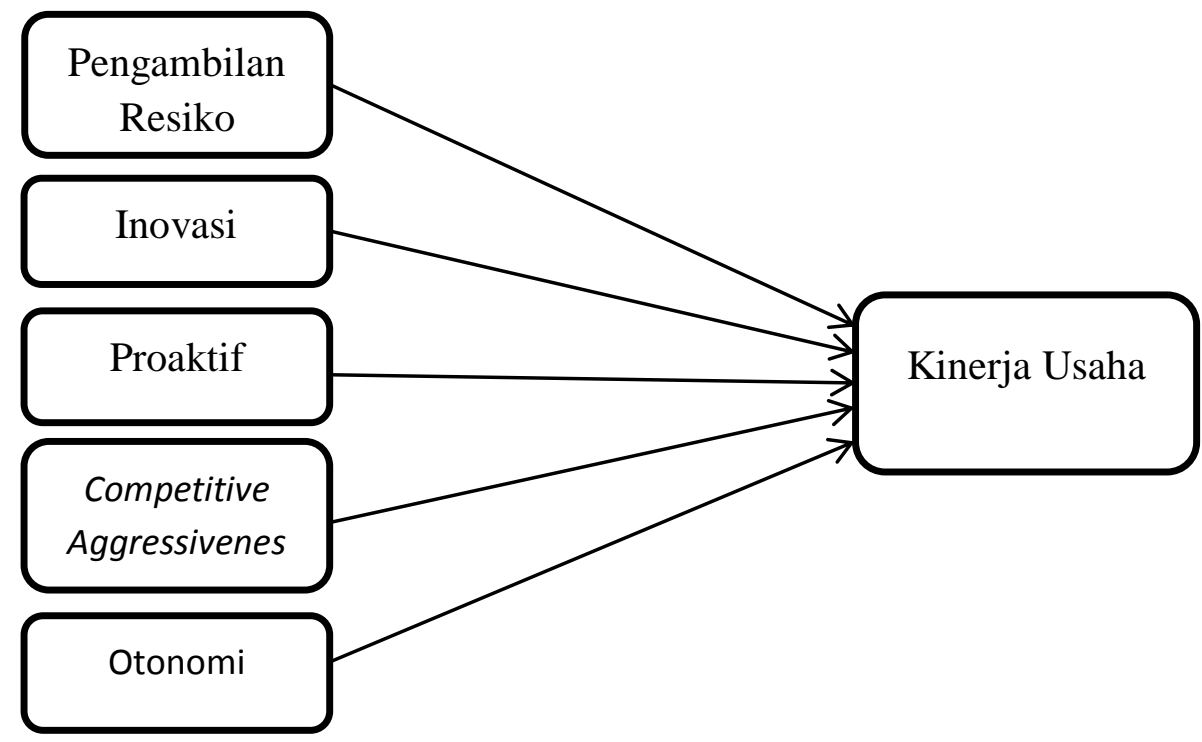

Gambar 1. Model Penelitian

\section{METODOLOGI}

Dalam penelitian ini menggunakan desain penelitian kuantitatif dan deskriptif. Penelitian deskriptif bertujuan untuk dapat menjelaskan suatu keadaan peristiwa atau segala hal yang berkaitan dengan variabel-variabel yang dapat dijelaskan dengan menggunakan angak-angka atau huruf-huruf. Penelitian ini menggunakan penelitian deskriptif karena adanya hipotesis untuk dapat menjawab masalah yang ada, terdapat masalah, menggunakan metode survey, dan dapat menggunakan teknik kuantitatif. Penelitian kuantitatif merupakan proses untuk menemukan suatu pengetahuan dimana hasil yang didapat berupa data angka yang sebagai alat untuk menganalisis keterangan mengenai hal apa yang ingin diketahui.

Penelitian ini menggunakan non-probability sampling sebagai teknik pemilihan sampel teknik dalam pemilihan sampel yang tidak semua anggota populasi memiliki kesempatan yang sama untuk dapat dipilih sebagai responden. Karena adanya keterbatasan waktu maka 
penelitian ini menggunakan teknik sampel judgemental sampling dengan menggunakan google form secara elektronik. Penelitian ini menggunakan sampel sebanyak 60 sampel.

Pengukuran variabel-variabel dalam penelitian ini mengacu pada penelitian sebelumnya antara lain sebagai berikut:

\begin{tabular}{ccc} 
Variabel & Indikator & Acuan \\
\hline Pengambilan Resiko & 3 item & Buli Bereket Mamo (2017) \\
\hline Inovasi & 3 item & Buli Bereket Mamo (2017) \\
\hline Proaktif & 3 item & Buli Bereket Mamo (2017) \\
\hline Competitive Aggressiveness & 3 item & Buli Bereket Mamo (2017) \\
\hline Otonomi & 5 item & Buli Bereket Mamo (2017) \\
\hline Kinerja Usaha & 5 item & Al Mamun \& Fazal (2018)
\end{tabular}

\section{Hasil Uji Statistik}

Analisis validitas, baik convergent validity maupun discriminant validity, telah dilakukan dengan menggunakan analisis loading factors dan cross loadings. Hasilnya seluruh variabel dan indikator dalam penelitian ini valid untuk digunakan. Keenam variabel yang digunakan dalam penelitian ini juga dinyatakan reliabel

$\mathrm{R}^{2}$ digunakan untuk mengukur seberapa besar variabel pengambilan resiko, inovasi, proaktif, competitive aggressiveness, dan otonomi dapat menjelaskan variabel kinerja usaha. $R$ square sebesar 0,406 menjelaskan bahwa besar pengaruh pengambilan resiko, inovasi, proaktif, competitive aggressiveness, dan otonomi terhadap kinerja usaha ialah sebesar 40,6\%, sisanya sebesar 59.4\%. Selanjutnya, hasil pengujian $\mathrm{Q}^{2}$ menunjukan nilai sebesar 0,203 untuk variabel kinerja usaha yang artinya nilai predictive relevance $\left(\mathrm{Q}^{2}\right)$ dalam penelitian ini lebih besar dari pada 0 .

Hasil analisis data secara singkat dapat dilihat pada Tabel 1.

Tabel 1

Hasil Pengujian Hipotesis

\begin{tabular}{lccc}
\multicolumn{1}{c}{ Variabel } & Original Sample & $\boldsymbol{t}$-statistics & $\boldsymbol{p}$-values \\
\hline $\begin{array}{l}\text { Pengambilan Resiko -> Kinerja } \\
\text { Usaha }\end{array}$ & 0.323 & 2.455 & $\mathbf{0 . 0 1 4}$ \\
\hline Inovasi -> Kinerja Usaha & 0.212 & 2.021 & $\mathbf{0 . 0 4 4}$ \\
\hline Proaktif -> Kinerja Usaha & 0.084 & 0.578 & $\mathbf{0 . 5 6 8}$ \\
\hline $\begin{array}{l}\text { Competitive Aggressiveness } \text {-> } \\
\text { Kinerja Usaha }\end{array}$ & 0.062 & 0.397 & $\mathbf{0 . 6 9 1}$ \\
\hline Otonomi -> Kinerja Usaha & 0.222 & 2.025 & $\mathbf{0 . 0 4 3}$ \\
\hline
\end{tabular}

Dari hasil pengujian hipotesis yang didapat untuk pengaruh pengambilan resiko terhadap kinerja usaha dalam penelitian ini menghasilkan nilai $t$-statistics sebesar 2.455 dan memiliki nilai $p$-value 0.014 yang lebih rendah dari batas yang telah ditentukan yaitu sebesar yaitu 0.05 , yang artinya $\mathrm{H} 1$ signifikan, dengan itu dapat disimpulkan bahwa inovasi memiliki pengaruh terhadap kinerja usaha

Dari hasil pengujian hipotesis yang didapat untuk pengaruh inovasi terhadap kinerja usaha dalam penelitian ini menghasilkan nilai t-statistics sebesar 2.021 dan memiliki nilai pvalue 0.044 yang lebih rendah dari batas yang telah ditentukan yaitu sebesar yaitu 0.05 , yang 
artinya $\mathrm{H} 2$ signifikan, dengan itu dapat disimpulkan bahwa inovasi memiliki pengaruh terhadap kinerja usaha

Dari hasil pengujian hipotesis yang didapat untuk pengaruh proaktif terhadap kinerja usaha dalam penelitian ini menghasilkan nilai $t$-statistics sebesar 0.578 dan memiliki nilai $p$-value 0.568 yang lebih besar dari batas yang telah ditentukan yaitu sebesar yaitu 0.05 , yang artinya H3 tidak signifikan dengan itu dapat disimpulkan bahwa proaktif tidak memiliki pengaruh terhadap kinerja usaha

Dari hasil pengujian hipotesis yang didapat untuk pengaruh competitive aggressiveness terhadap kinerja usaha dalam penelitian ini menghasilkan nilai $t$-statistics sebesar 0.397 dan memiliki nilai $p$-value 0.691 yang lebih besar dari batas yang telah ditentukan yaitu sebesar yaitu 0.05 , yang artinya $\mathrm{H} 4$ tidak signifikan, dengan itu dapat disimpulkan bahwa competitive aggressiveness tidak memiliki pengaruh terhadap kinerja usaha

Dari hasil pengujian hipotesis yang didapat untuk pengaruh otonomi terhadap kinerja usaha dalam penelitian ini menghasilkan nilai t-statistics sebesar 2.025 dan memiliki nilai p-value 0.043 yang lebih rendah dari batas yang telah ditentukan yaitu sebesar yaitu 0.05 , yang artinya H5 signifikan, dengan itu dapat disimpulkan bahwa otonomi memiliki pengaruh terhadap kinerja usaha

Pengujian effect size dilakukan untuk dapat mengetahui seberapa besar efek yang menunjukan variabel tertentu tidak diikutsertakan dalam model penelitian. Hasilnya menunjukan dari hasil pengujian effect size dapat dijelaskan variabel pengambilan resiko memiliki efek yang besar terhadap kinerja usaha dengan nilai sebesar 0,121. Variabel Inovasi memiliki efek yang sedang terhadap kinerja usaha dengan nilai 0.056 , variabel proaktif memiliki efek yang sangat kecil terhadap kinerja usaha dengan nilai sebesar 0.006, variabel competitive aggressiveness merupakan variabel yang pengaruh terhadap kinerja usaha sangat kecil dengan nilai 0.005 dan terakhir otonomi yang memiliki pengaruh sedang terhadap kinerja usaha dengan nilai sebesar 0.061.Selain itu, dilakukan pula pengujian goodness of fit (GoF) untuk menggambarkan seberapa besar nilai variabel dependen dapat memprediksi keseluruhan model. Berdasarkan dari hasil perhitungan Goodness of Fit (GOF) diatas sebesar 0.4898 dapat dijelaskan bahwa model yang digunakan dalam penelitian ini memiliki kecocokan yang tergolong besar. Sesuai menurut Tenenhaus, et al (2005) yang menyatakan bila nilai Gof 0,1 maka dinyatakan kecil, bila nilai GoF 0,25 maka dinyatakan sedang dan bila nilai GoF 0,36 dinyatakan besar.

\section{DISKUSI}

Pada hasil pengujian hipotesis yang pertama menunjukan bahwa pengambilan resiko memiliki pengaruh terhadap kinerja usaha konveksi di Jakarta Barat. Hasil pengujian ini sesuai dengan hasil penelitian yang dikemukakan oleh Hughes dan Morgan (2007) yang menyatakan pengambilan resiko mempunyai hubungan positif terhadap kinerja usaha. Selain itu menurut Rauch et al (2009) juga menyatakan bahwa terdapat hubungan positif antara pengambilan risiko dan kinerja usaha yang dianggap sebagai pandangan yang dominan. Pengambilan resiko merupakan hal yang penting untuk meningkatkan kinerja usaha konveksi yang secara langsung juga dapat meningkatkan performa usaha yang sedang dijalankan. Keberanian mengambil resiko dalam bersaing dapat mendukung tingkat daya saing dari bidang usaha konveksi ini, maka dengan berani mengambil resiko akan mendorong usaha konveksi bekerja dengan lebih keras sehingga perusahaan dapat meningkatkan kinerja usaha. Selanjutnya, berdasarkan hasil pengujian hipotesis kedua $\left(\mathrm{H}_{2}\right)$ menjelaskan Pada hasil pengujian hipotesis yang kedua menunjukan bahwa inovasi memiliki pengaruh terhadap kinerja usaha konveksi di Jakarta Barat. Inovasi memiliki arti ide atau gagasan untuk membuat baru atau mengembangkan 
produk atau jasa yang dapat mempengaruhi sumber daya pemasaran Hasil pengujian ini sesuai dengan hasil penelitian yang dikemukakan oleh Calantone, Cavusgil dan Zhao (2002) menyatakan bahwa inovasi memiliki dampak positif terhadap kinerja usaha. Hurley dan Hult (1998) yang juga menyatakan inovasi pada akhirnya akan menghasilkan keunggulan yang kompetitif dan organisasi yang memiliki kapasitas inovatif yang besar dapat menghasilkan kinerja yang superior. Maka dapat disimpulkan perusahaan yang menerapkan inovasi akan menciptakan keunggulan kompetitif dan mencapai keberhasilan superior Hal ini menunjukan bahwa inovasi merupakan hal yang penting dalam meningkatkan kinerja usaha konveksi. Selanjutnya berdasarkan hasil pengujian hipotesis ketiga $\left(\mathrm{H}_{3}\right)$ menjelaskan hasil pengujian hipotesis yang ketiga, menyatakan bahwa proaktif tidak berpengaruh terhadap kinerja usaha konveksi. Penelitian ini tidak sesuai dengan pernyataan yang telah dikemukakan oleh Hughes dan Morgan (2007) yang menyatakan proaktif cenderung berkaitan dengan kinerja usaha. Tetapi hasil hipotesis ketiga ini sesuai dengan Sangen (dalam Umar 2015) yang menyatakan bahwa proaktif tidak memiliki hubungan positif terhadap kinerja usaha. Sifat yang proaktif sebenarnya diperlukan bagi perusahaan yang membutuhkan karyawan yang inisiatif dalam melakukan pekerjaanya. Namun dalam bidang usaha yang diteliti yaitu konveksi. Usaha konveksi tidak memerlukan karyawan yang proaktif dalam meningkatkan kinerja usaha karena dalam usaha ini mereka hanya membuat barang sesuai pesanan sehingga mereka hanya menyelesaikan pesanan sesuai yang dipesan pelanggan maka usaha ini tidak memerlukan karyawan yang inisiatif. Oleh karena itu proaktif tidak berhubungan dalam meningkatkan kinerja usaha konveksi. Selanjutnya berdasarkan hasil hipotesis keempat $\left(\mathrm{H}_{4}\right)$ menjelaskan bahwa competitive aggressiveness tidak berpengaruh terhadap kinerja usaha konveksi. Hasil penelitian ini tidak sesuai dengan pernyataan yang dikemukakan oleh Setiawan, Erdogan dan Ouglana (2015) menyatakan bahwa competitive aggressiveness berpengaruh positif terhadap kinerja perusahaan. Dalam bidang usaha konveksi, competitive aggressiveness tidak berpengaruh terhadap usaha konveksi karena dalam bisnis ini mereka juga memerlukan satu sama lain apabila kapasitas produksi mereka sedang penuh mereka meminta rekan konveksi lainnya untuk membantu mengerjakan pesanan sehingga dapat selesai dengan tepat waktu, maka itu competitive aggressiveness ini tidak berpengaruh dalam meningkatkan kinerja usaha konveksi. Selanjutnya berdasarkan hasil hipotesis yang kelima $\left(\mathrm{H}_{5}\right)$ menyatakan bahwa otonomi memiliki pengaruh terhadap kinerja usaha konveksi di Jakarta Barat. Otonomi memiliki arti sebuah kemampuan individu dalam pengambilan keputusan dan bertindak kreatif secara mandiri dalam mengatasi persoalan. Hasil penelitian ini sesuai dengan pendapat Bandura (1997) bahwa otonomi memiliki hubungan positif terhadap kinerja usaha. Hal ini juga sesuai dengan penelitian Wulandary (2018) yang menyatakan bahwa otonomi mempunyai dampak yang signifikan dan positif terhadap kinerja karena otonomi menyampaikan kebebasan kepada karyawan untuk mendorong mereka untuk menjadi mandiri. Maka dapat disimpulkan jika perusahaan menerapkan otonomi maka kinerja usaha dapat meningkat karena dapat mengikuti keyakinan dari dirinya sendiri dan leluasa dalam mengambil keputusan dan aktivitas kreatif dalam memberikan ide dan gagasan untuk meningkatkan bisnis. Otonomi dapat berpengaruh terhadap bidang usaha konveksi karena dengan memberikan kebebasan berpikir dan bertindak kepada karyawan dalam mengerjakan pekerjaanya dapat membuat karyawan bekerja lebih cepat dengan cara nya masing-masing sehingga dapat meningkatkan kinerja usaha konveksi.

\section{KESIMPULAN}

Berdasarkan hasil penelitian analisis dan pembahasan, maka dapat disimpulkan sebagai berikut: Pertama, terdapat pengaruh antara pengambilan resiko terhadap kinerja usaha 
konveksi di Jakarta Barat. Kedua, terdapat pengaruh antara inovasi terhadap kinerja usaha konveksi di Jakarta Barat. Ketiga, tidak terdapat pengaruh antara proaktif terhadap kinerja usaha konveksi di Jakarta Barat, keempat, tidak terdapat pengaruh antara competitive aggressiveness terhadap kinerja usaha konveksi di Jakarta Barat dan kelima, terdapat pengaruh antara otonomi terhadap kinerja usaha konveksi di Jakarta Barat.

Peneliti menyarankan untuk para pengusaha konveksi untuk berani mengambil resiko dalam menjalankan usahanya sehingga dapat melihat peluang yang ada dan dapat untuk mengubah suatu ide menjadi sebuah kesempatan usaha. Kedua pengusaha konveksi diharapkan dapat lebih berinovasi dalam mengembangkan produk Ketiga, menyarankan kepada pengusaha konveksi agar terus dapat menyaingi pesaingnya dengan mencoba menerapkan proaktif dan competitive aggressiveness sehingga dapat meningkatkan kualitas dan kemajuan usaha dan yang keempat pengusaha konveksi diharapkan juga dapat menerapkan otonomi agar dapat bekerja secara mandiri, membuat keputusan, dan mengambil keputusan untuk membawa suatu konsep bisnis yang jelas dan membawa usaha ini menuju keberhasilan dan terakhir peneliti selanjutnya diharapkan dapat meneliti dengan variabel-variabel lain diluar variabel ini seperti kualitas manajemen, efektivitas, product quality dan variabel lainnya yang dapat mempengaruhi kinerja usaha.

\section{DAFTAR PUSTAKA}

Al Mamum, A., \& Fazal, S. A. (2018). Effect of entrepreneurial orientation on competency and micro-enterprise performance. Asia Pacific Journal of Innovation and Entrepreneurship.

Bandura, A. (1997). Self-efficacy: The Exercise of Control. W.H. Freemand and company.

Basrowi. (2011). Kewirausahaan untuk perguruan tinggi. Bogor: Ghalia Indonesia.

Buli B. M. (2017) "Entrepreneurial orientation, market orientation and performance of SMEs in the manufacturing industry: Evidence from Ethiopian enterprises", Management Research Review, Vol. 40 Issue: 3, pp.292-309, Retrieved from Emerald.

Calantone, R. J., Çavuşgil, S. T., \& Zhao, Y. (2002). Learning orientation, firm innovation capability, and business performance. Industrial Marketing Management, 31, 515-524

Ernawati, F. Y. (2016). Model Peningkatan Keunggulan Kompetitif Melalui Kinerja Perusahaan. Jurnal STIE Semarang, 8(3), 65-82.

Hughes, M., \& Morgan, R. E. (2007). Deconstructing the relationship between entrepreneurial orientation and business performance at the embryonic stage of firm growth. Industrial marketing management, 36(5). 651-661.

Hurley, R. \& Hult, G. T. (1998). Inovation, market orientation, and organizational learing: an integration and empirical examination.Journal of marketing, 62(3),45-54.

Jahangir, Y. F., Arash, R., \& Amer, D. N. (2013). Social capital and organizational innovation: the mediating effect of entrepreneurial orientation. Journal of Community Positive Practices, 13(2), 22-40.

Johannessen, J. A., Olaisen, J., \& Olsen, B. (1999) 'Managing and organizing innovation in the knowledge economy', European Journal of Innovation Management, Vol. 2, No. 3, pp. 116-128. 
Keh, H.T., Foo, M.D., \& Lim, B.C. (2002), “Opportunity evaluation under risky conditions: the cognitive processes of entrepreneurs", Entrepreneurship theory and practice, Vol. 27 No. 2,pp. 125-148.

Knight, G. (2000). Entrepreneurship and Marketing Strategy: the SME Under Globalization. Journal of International Marketing, ISSN 1069-031X, Vol.8, No.2 (2000).

Kristiawan, M., Suryanti, I., Muntazir, M., Ribuwati, A., \& AJ, A. (2018). Inovasi Pendidikan. Jawa Timur: Wade Group National Publishing.

Lumpkin G. T. \& Dess G. (1996). Clarfying The Entrepreurial Orintation Construct and Linking It to Perfomance. Academy of Management Review. Vol. 21:135-172.

Lumpkin, G. T. \& Dess, G. G. (2001). Linking Two Dimensions of EO to Firm Performance: The Moderating Role of Environment and Industry Life Cycle. Journal Business Venturing. 16 (5), $429-451$.

Nanda, E. Q. (2015). Pengaruh Orientasi Kewirausahaan pada Perusahaan Makanan dan Minuman di Surabaya. Agora, 3(1), 706-715.

Purnomo, R. \& Lestari. (2010). Pengaruh kepribadian, self-efficacy, dan locus of control terhadap persepsi kinerja usaha skala kecil dan menegah. Jurnal Bisnis dan Ekonomi, 17(2),144-160.

Ramadani, V., \& Gerguri, S. (2011). Innovations: principles and strategies. Strategic Change, 20(3-4).

Rauch, A., Wiklund, J., Lumpkin, G. T., \& Frese, M. (2009). Entrepreneurial orientation and business performance: An assessment of past research and suggestions for the future. Entrepreneurship theory and practice, 33(3), 761-787.

Setiawan, H., Erdogan, B., \& Ogunlana, S. O. (2015). Competitive aggressiveness og contractors:A study of Indonesia. Procedia Engineering, 125, 68-74.

Suci, R. P. (2009). Peningkatan kinerja melalui orientasi kewirausahaan,kemampuan manajemen, dan strategi bisnis. Jurnal Manajemen dan kewirausahaan, 11(1), 46-58.

Tenenhaus, Michel, Vinci, V. E., Chatelin, Y.-M., \& Lauro, C. (2005). PLS path modeling. Computational Statistics \& Data Analysis, 48 no 1, 159-205.

Umar, Z. A. (2015). Peran Kemampuan Manajemen dan Orientasi Pasar Sebagai Mediasi Pengaruh Orientasi Kewirausahaan Terhadap Kinerja Bisnis (Studi Pada Perusahaan Industri Kecil Pangan di Provinsi Gorontalo). Disertasi Doktor (DP2M), 2(998).

Wibowo. (2010). Manajemen Kinerja. Jakarta: Rajawali Pers.

Wright,P.,Kroll,M.,Pray,B.,\&Lado,A.(1995).Strategicorientations,competitive advantage, and business performance. Journal of Business Research, 33, 143-151.

Wulandary, A. (2018). Pengaruh Orientasi Kewirausahaan Terhadap Kinerja Usaha Pada Industri UMKM Abon Ikan Di Kota Makassar The Effect of Entrepreneurship Orientation toward Business Performance In Fish Abon SME Industry In Makassar City. Journal of Food System \& Agribusiness, 1(2). 